\title{
Usinagem fotovídeo: sensibilização para a preservação do patrimônio público escolar durante a pandemia da Covid-19
}

Usinagem fotovideo: raising awareness for the preservation of public school heritage during the Covid-19 pandemic

Mecanizado fotovideo: sensibilización para la preservación del patrimonio de las escuelas públicas durante la pandemia Covid-19

Recebido: 02/09/2021 | Revisado: 09/09/2021 | Aceito: 14/09/2021 | Publicado: 16/09/2021

Simone Reis Mendes

ORCID: https://orcid.org/0000-0001-7388-6891 Instituto Federal de Educação, Ciência e Tecnologia do Triângulo Mineiro, Brasil E-mail: simonereis@iftm.edu.br

Ernani Viriato de Melo

ORCID: https://orcid.org/0000-0002-8450-3478 Instituto Federal de Educação, Ciência e Tecnologia do Triângulo Mineiro, Brasil E-mail: ernanimelo@iftm.edu.br

\begin{abstract}
Resumo
Esta pesquisa desenvolvida com os alunos do Ensino Médio Integrado (EMI) do Instituto Federal do Triângulo Mineiro - Campus Uberaba (IFTM-URA), foi motivada a partir das ocorrências de atos de depredação do patrimônio público escolar (PPE), no período pré-pandemia, e percebeu-se a necessidade de uma intervenção pedagógica para trabalhar a sensibilização para a preservação do PPE. Durante a pandemia da Covid-19 a presente pesquisa desenvolveu um audiovisual, denominado Usinagem FotoVídeo, onde alunos relataram a importância do espaço escolar para eles. O audiovisual foi visualizado por 94 alunos e $91 \%$ informaram que a Usinagem FotoVídeo contribuiu para a conscientização do PPE e 97\% avaliaram como importante o protagonismo do aluno nas ações institucionais. Conclui que, a produção audiovisual como ferramenta para aprendizagem pode ser utilizada pelos educadores, independente da sua área de atuação, para tanto, é imprescindível que os alunos estejam motivados para que esse modal esteja mais próximo do entretenimento, do lazer e que a aprendizagem seja uma consequência.
\end{abstract}

Palavras-chave: Sensibilização para a preservação; Patrimônio escolar; Pandemia Covid-19.

\begin{abstract}
This research, developed with Integrated High School (EMI) students at the Triângulo Mineiro Federal Institute Campus Uberaba (IFTM-URA), was motivated by the occurrence of acts of depredation of public school property (PPE), in the pre- pandemic, and the need for a pedagogical intervention to raise awareness for the preservation of the PPE was perceived. During the Covid-19 pandemic, this research developed an audiovisual, called Usinagem FotoVídeo, where students reported the importance of the school space for them. The audiovisual was viewed by 94 students and $91 \%$ informed that the FotoVídeo Usinagem contributed to the awareness of the PPE and 97\% evaluated as important the role of the student in institutional actions. It concludes that audiovisual production as a tool for learning can be used by educators, regardless of their area of expertise, therefore, it is essential that students are motivated so that this modal is closer to entertainment, leisure and that learning is a consequence.
\end{abstract}

Keywords: Preservation awareness; School assets; Covid-19 pandemic.

\section{Resumen}

Esta investigación, desarrollada con estudiantes de Bachillerato Integrado (EMI) del Instituto Federal Triângulo Mineiro - Campus Uberaba (IFTM-URA), fue motivada por la ocurrencia de actos de depredación de propiedad pública escolar (PPE), en la prepandémica, y se percibió la necesidad de una intervención pedagógica de sensibilización para la preservación de los EPI. Durante la pandemia de Covid-19, esta investigación desarrolló un audiovisual, denominado Usinagem FotoVídeo, donde los estudiantes informaron sobre la importancia del espacio escolar para ellos. El audiovisual fue visto por 94 estudiantes y el $91 \%$ informó que el FotoVídeo Usinagem contribuyó a la concienciación de los EPI y el 97\% evaluó como importante el papel del estudiante en las acciones institucionales. Se concluye que la producción audiovisual como herramienta para el aprendizaje puede ser utilizada por los educadores, independientemente de su área de especialización, por ello, es fundamental que los estudiantes estén motivados para que esta modalidad se acerque más al entretenimiento, al ocio y que el aprendizaje sea una consecuencia.

Palabras clave: Conciencia para la preservación; Patrimonio escolar; Pandemia de Covid-19. 


\section{Introdução}

Este estudo trabalha a temática sensibilização para a preservação do patrimônio público escolar (PPE), protagonizada pelos alunos do Ensino Médio Integrado (EMI), por meio da produção audiovisual. A pesquisa teve início no ano de 2019, ainda quando as aulas eram na modalidade presencial, e o Instituto Federal do Triângulo Mineiro - Campus Uberaba (IFTMURA), assim como as demais escolas públicas, vivenciava a problemática da depredação do PPE.

Para cursar o EMI, o alunado adolescente deve permanecer na escola nos períodos matutino e vespertino durante quase todos os dias da semana. Segundo o Estatuto de Criança e do Adolescente, no Artigo 20. "Considera-se criança, para os efeitos desta Lei, a pessoa até doze anos de idade incompletos, e adolescente aquela entre doze e dezoito anos de idade". (Brasil, 1990). Para os jovens descomprometidos com os estudos, o que atenua a imposição aulista, são as atividades que permitem a socialização, como: o esporte, o lazer, as atividades culturais e extramuros. A indiferença quanto ao aprendizado reflete negativamente em todo o contexto escolar. $\mathrm{O}$ educando apresenta dificuldades no aprendizado, no relacionamento com aqueles que estão, de fato, comprometidos com o ensino e com a aprendizagem e, não se vendo como parte integrante, não tem apreço pela instituição. Reflete também no contexto ambiental, visto que, alguns alunos expressam as suas reações depredando o que está a sua volta.

A desmotivação dos alunos e o desinteresse explicito por aquilo que o professor pretende ensinar interferem no comportamento, deixando muitas vezes o aluno agressivo, são formas inadequadas sobre os métodos de ensino ou sobre as estratégias de relação na aula que exigem do professor clareza na negociação naquilo pretende fazer trabalhar com os alunos, quando não há regras que estejam em comum acordo entre ambos, o resultado é a insatisfação e indisciplina (Rosa, 2010, p. 147).

Os atos de vandalismo mais frequentes são: escrever palavras de baixo calão nos banheiros, rabiscar portas, mesas, carteiras e paredes, quebrar vidros de janelas, espelhos dos banheiros, saboneteiras, papeleiras, lixeiras, lâmpadas e luminárias; fixação de papel higiênico molhado nas paredes; tirar lascas; queimar, danificar equipamentos e extintores de incêndio; danos na edificação; furtos; jogar lixo no chão, dentre outros. Esta relação de itens, alvo de vandalismo, também fez parte de uma pesquisa em que buscou-se avaliar a frequência de vandalismo, em escola pública de Florianópolis (SC), e os entrevistados foram os estudantes da sétima série do Ensino Fundamental à terceira série do Ensino Médio:

As sentenças apresentadas na questão foram: colocar os pés na parede; tirar lascas de uma porta; estragar um extintor de incêndio; riscar carteiras ou cadeiras; tirar lascas da carteira ou da cadeira; riscar paredes ou portas; quebrar uma lâmpada ou uma luminária; jogar lixo no chão; quebrar um vidro de janela; estragar saboneteiras, papeleiras ou lixeiros; retirar pastilha cerâmica de parede ou banco. Tais sentenças foram construídas a partir de prévias observações diretas do estado de conservação das instalações da escola (Felippe \& Kuhnen, 2012, p. 245).

Ambientes com aspectos negativos quanto à conservação propiciam os atos de depredação, interfere no bem-estar do aluno, no processo de aprendizagem e na conscientização de cuidado ambiental. Vieira, Morais, Barbosa, Maia e Alves (2012, p. 16) [...] os maiores prejudicados são os próprios alunos, que passam a ter equipamentos danificados, instalações depredadas, sem levar em conta o péssimo aspecto visual, que influencia diretamente no bem-estar dos alunos em processo de aprendizagem.

A problemática do vandalismo escolar vem sendo discutida em vários trabalhos. Vieira, Morais, Barbosa, Maia e Alves (2012) avaliou os atos de depredação e suas motivações no IFPB, revelando falta de consciência com aquilo que é público. Domingues e Silva (2017) propôs uma intervenção pedagógica em uma escola pública, colocando em prática uma ação de gestão escolar, ficando claro que a ação educacional se mostrou eficiente para a resolução de um problema local. 
Almeida (2018) trabalhou uma abordagem (auto) biográfica e obteve as respostas favoráveis para pensar no tratamento de uma educação ambiental dentro dos espaços escolares.

Visando aumentar o protagonismo dos alunos no ambiente escolar, alguns autores relatam a produção audiovisual como uma proposta de ensino que proporciona a participação ativa dos estudantes. Gomes (2011) vivenciou a experiência dos jovens do Projeto Curtas, de Blumenau/SC e descobriu que os modos de ver são afetados pela experiência de fazer cinema, que alguns sentidos são produzidos e outros modificados. Zanini (2013) apresentou o Projeto Cinema na Escola, desenvolvido em Santa Maria/RS, com fins específicos à produção de curtas metragens. Compreendeu que, com uma proposta de prática diferenciada, é possível aproximar e envolver o aluno em construções significativas para além do momento escolar. Lindenmeyer (2016) trabalhou a produção de curtas-metragens como estratégia tecnológica de autoria, aprendizagem e inclusão, concluindo que a educação tem que ser atraente e que o processo de aprendizagem deve privilegiar ações em que os alunos são protagonistas, autores da sua própria aprendizagem. Em outras palavras: o protagonismo dos alunos segue os modelos da Aprendizagem Baseada em Projetos (ABP) e o da Escola Nova Diretiva, ou seja, o aluno é um ser ativo, o propósito é aprender fazendo. (Cipolla, 2015, p. 569).

[...] são metodologias que possibilitam o aprender a aprender, bem como garantem o aprender fazendo. E são centradas no estudante, portanto, estes são vistos como sujeitos do processo de ensino-aprendizagem e como cidadãos. As metodologias são fundamentadas no princípio da pedagogia interativa, na concepção pedagógica crítica e reflexiva e têm como eixo central a participação ativa dos estudantes em todo o processo, incluindo todos os novos e diferentes cenários da prática.

Castaman e Rodrigues, (2020, p. 9) corroboram com a metodologia ativa ao enfatizarem que, no que tange ao ensino, o docente tem suas atribuições, porém, não deve ser o agente exclusivo da produção do conhecimento cabendo a ele estimular os estudantes a buscarem o conhecimento e a serem, também, responsáveis por sua formação intelectual.

Como solucionar a dicotomia: o público-alvo da escola, que são os estudantes, e a escola como o alvo, de atos de depredação, por parte deste mesmo público que não a reconhece e não a valoriza? Como transformar potenciais autores da depredação em atores da preservação do PPE? No sentido de responder esta pergunta de pesquisa, este trabalho desenvolveu uma produção audiovisual, denominada "Usinagem FotoVídeo".

Usinagem FotoVídeo é uma produção audiovisual protagonizado pelos alunos do EMI do IFTM-URA, que produziram seus vídeos, individuais, com base em fotografias do campus, em que eles relatam o carisma que eles têm pela escola. O palco para a atuação dos alunos protagonistas foi o ambiente virtual, respeitando o distanciamento social devido à Pandemia de Covid-19. Trata-se de uma atividade de extraclasse, utilizando os recursos educacionais disponíveis na internet. O processo de sensibilização se deu com a socialização do audiovisual, tendo como público alvo os alunos do EMI. O vídeo, como dispositivo pedagógico é comentado por Pires (2010, p. 291):

O vídeo constitui uma ferramenta e um dispositivo pedagógico importante para os adolescentes por sua capacidade de visualizar os próprios conflitos e o dos outros, por sua ludicidade e tecnicidade e por permitir a participação de todos, ainda que alguns se situem atrás da câmera, protegidos da emoção ou do choque de um confronto direto com o outro e/ou com a sua cultura. Por mais paradoxal que isso possa parecer, é também uma situação que pode se transformar numa abertura em direção ao outro, ou seja, dentro de uma relação dialógica, o eu e o outro veem o mundo de perspectivas diferentes. Isso não significa que estão incomunicáveis, mas em uma experiência audiovisual, de lugares diferentes, uma negociação permanente de produção de linguagem torna-se possível com a mediação da câmera.

\section{Metodologia}

Trata-se de uma pesquisa-ação voltada para a promoção de mudanças comportamentais, ainda no período da pandemia do Covid-19, quanto à valorização do PPE. Em nenhum momento trabalhou-se um adestramento comportamental, e 
sim o voluntariado, em um ambiente agradável. Segundo Thiollent (2011, p. 10): A pesquisa-ação se apresenta como método de pesquisa inserida em prática ou ações sociais, educacionais, técnicas, estéticas, etc.

Quando das aulas, ainda, presenciais foram detectados os atos de vandalismo contra o PPE e a necessidade de uma intervenção pedagógica para a sensibilização e valoração da escola, que nas palavras de Boarini (2013, p. 129), deve ser um exercício diário: "No caso do ambiente escolar, a disciplina é um exercício diário que ocorre no cotidiano da sala de aula. Deve ser construída e administrada no dia a dia por todos os envolvidos na educação". Santagueda; Cantalice; Silva e Mafort (2019, p. 13) consideram que: "Torna-se interessante que trabalhos como este sejam sempre desenvolvidos ao longo do período letivo, fazendo com que temas relacionados a educação ambiental se tornem uma realidade constante no ambiente escolar".

Em março de 2021 completou 01 (um) ano de aulas remotas e, mesmo sem a presença do seu público (alunos, professores, servidores...), o IFTM-URA vem realizando todos os trabalhos de manutenção predial, de jardinagem, pinturas e limpeza, na eminência do retorno às aulas presenciais e ou híbridas. Neste contexto os pesquisadores elaboraram e aplicaram a atividade extraclasse, Usinagem FotoVídeo, no sentido de fomentar o protagonismo estudantil no processo de sensibilização para a preservação do PPE, durante a pandemia da Covid-19, por meio da produção audiovisual. Moura (2010, p. 282) esclarece que "O protagonismo juvenil tem como cerne o envolvimento dos educandos no exercício do voluntariado social, com uma prática que seria servidora, crítica, construtiva, criativa, solidária e voltada para a operacionalização de soluções imediatas".

Entramos em contato com alguns professores e solicitamos que divulgassem a atividade Usinagem FotoVídeo e estimulassem os seus alunos a participarem. Os professores relataram que os alunos foram surpreendidos pela questão da pandemia e que ainda estavam se adaptando com o ensino à distância, mas, se colocaram à disposição para divulgar a atividade extraclasse. Encaminhamos para os professores o audiovisual explicativo/convite1 e algumas fotos do IFTM-URA para divulgação entre os alunos. Para a elaboração do audiovisual contamos com 06 alunos que, produziram os seus vídeos e encaminharam, juntamente com uma foto do campus, para o e-mail e/ou WhatsApp dos pesquisadores. Os vídeos foram unificando e editados. Foram inseridos o design da Usinagem FotoVídeo, o quadro de abertura, frases de sensibilização, o quadro de encerramento, os créditos aos alunos protagonistas e trilhas sonoras bem descontraídas.

Após a conclusão da produção audiovisual o mesmo foi inserido no questionário, elaborado no Google Forms. O link de acesso ao questionário foi compartilhado com os coordenadores dos cursos EMI, que se disponibilizaram no sentido de encaminhamento da pesquisa para as turmas do EMI. O questionário foi aplicado no período de 23 de março a 12 de abril de 2021, totalizando 94 respondentes, sendo 74,5\% do Curso Técnico em Administração, 20,2\% do Curso Técnico em Agropecuária e 5,3\% do Curso Técnico em Alimentos.

A atividade extraclasse foi desenvolvida em 06 etapas, ilustrada na Figura 1.

${ }^{1}$ Convite disponível em https://youtu.be/wLjNgbQ8Kfc. 
Figura 1 - Etapas da Usinagem FotoVídeo.

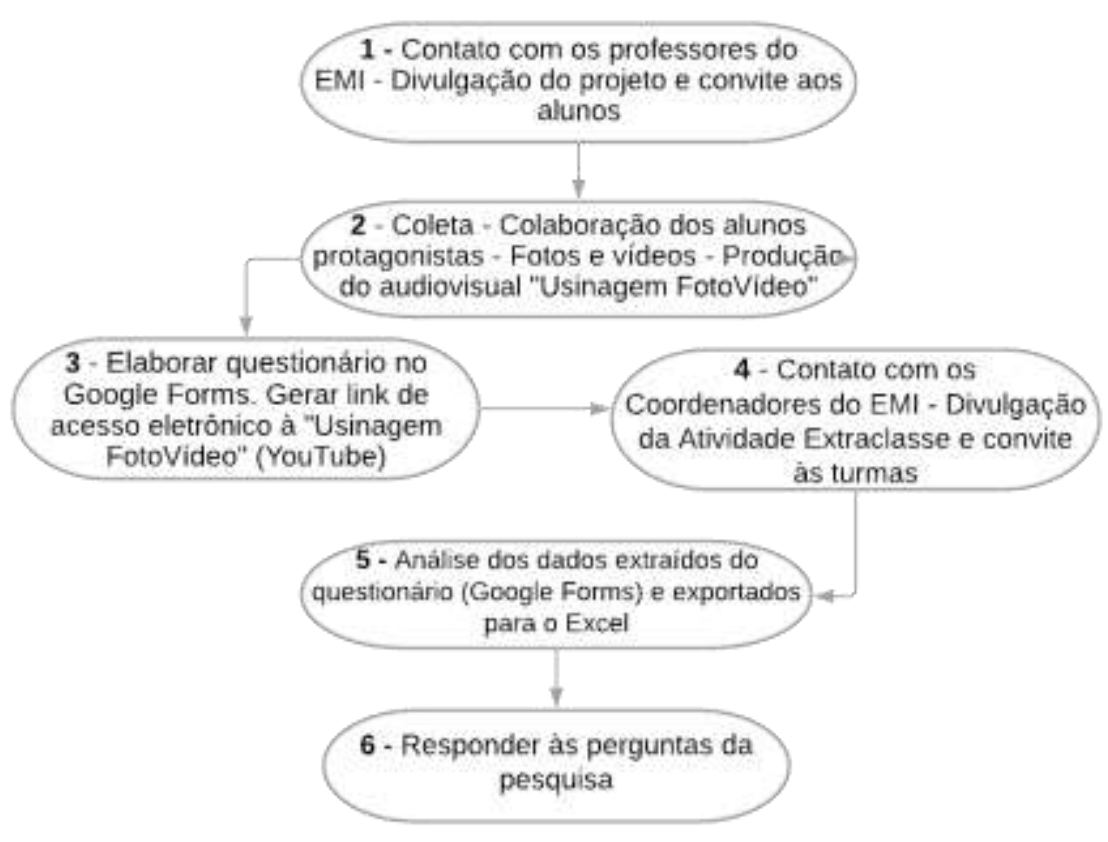

Fonte: Autores (2021).

$\mathrm{Na}$ etapa 1encaminhamos, por E-mail e WhatsApp, um convite para todos os alunos dos cursos EMI, contextualizando e convidando, os potenciais alunos protagonistas, a participarem da atividade extraclasse. A Etapa 2 consistiu na coleta, por e-mail e WhatsApp, dos materiais produzidos pelos participantes protagonistas e início ao processo de edição dos vídeos. Registra-se que o direito de uso de imagem foi autorizado pelo responsável, legal, de cada aluno protagonista. A Formulação do questionário, no Google Forms, foi na Etapa 3. Neste questionário buscou-se identificar de qual curso era o aluno respondente, para temos uma dimensão da participação por curso. Sondou-se qual o nível de sentimento de pertencimento à escola, para se ter uma noção do carinho e apreço que o aluno tem pela instituição. Buscou-se esquadrinhar as reflexões dos respondentes quanto à importância do espaço escolar, neste momento de pandemia, para sabermos se o distanciamento, físico, da escola, promoveu algum sentimento de valorização do ambiente escolar. Avaliou-se a qualidade do conteúdo do vídeo, bem como, o alcance obtido com o objetivo de promover a conscientização da preservação do PPE. Buscou-se, também, avaliar o grau de importância das ações voltadas para a preservação do patrimônio escolar e o grau de importância do protagonismo dos alunos em algumas ações do IFTM - no que tange a participação na elaboração, execução e reflexão. O questionário foi finalizado disponibilizando espaço para receber os comentários e sugestões, com o objetivo de aprimorar a atividade extraclasse. Já na Etapa 4 - Encaminhamos (por e-mail e WhatsApp), o link de acesso ao questionário (Google Forms) foi compartilhado com os coordenadores de cursos, com vistas à divulgação e convite às turmas do EMI do IFTM-URA, para assistirem o vídeo e responderem ao questionário. A análise dos dados, mencionados na etapa 3, ocorreu na Etapa 5.Procurou-se saber, na Etapa 6, se o protagonismo estudantil e a produção audiovisual são ferramentas importante para trabalhar a conscientização da preservação do PPE durante a pandemia da Covid-19.

A atividade extraclasse, denominada Usinagem FotoVídeo: “A Conscientização da Preservação do Patrimônio Público Escolar, Protagonizada pelos Alunos do Ensino Médio Integrado, por Meio da Produção Audiovisual", está disponível no Youtube2.

\footnotetext{
${ }^{2}$ Usinagem FotoVídeo disponível em https://www.youtube.com/watch?v=4JUZhj1MTdw.
} 
Foram 124 acessos, o vídeo teve 94 visualizações e o Google Forms contabilizou 94 respondentes. Os alunos assistiram e avaliaram: o vídeo, o grau de importância do protagonismo dos alunos, o grau de importância das ações voltadas para a preservação do PPE, registraram os seus comentários, sugestões e reflexões sobre o distanciamento imposto pela pandemia e as aulas remotas.

\section{Resultados e Discussão}

Após 03 (três) semanas as participações formam encerradas e o Google Forms contabilizou 94 respondentes. Apuramos, conforme Gráfico 1, que 78 de 94 pessoas (82\%) indicaram que o objetivo de "utilizar a produção audiovisual como ferramenta para que os alunos atuem como protagonistas na extensão do conhecimento e socialização das atividades desenvolvidas no IFTM", foi atingido. 76 de 94 pessoas (80\%) indicaram que o objetivo de "destacar a importância do patrimônio público para a comunidade escolar", foi alcançado, e por fim, 84 de 94 (89\%) indicaram que o objetivo de "evidenciar o compromisso, individual e coletivo, que temos, em preservar o PPE" também foi alcançado. Vale ressaltar que os respondentes indicaram ao menos um objetivo, ou seja, nenhum respondente marcou a opção "Nenhum dos objetivos".

Gráfico 1 - Na sua opinião, o vídeo “Usinagem FotoVídeo” alcançou qual(is) objetivo(s):

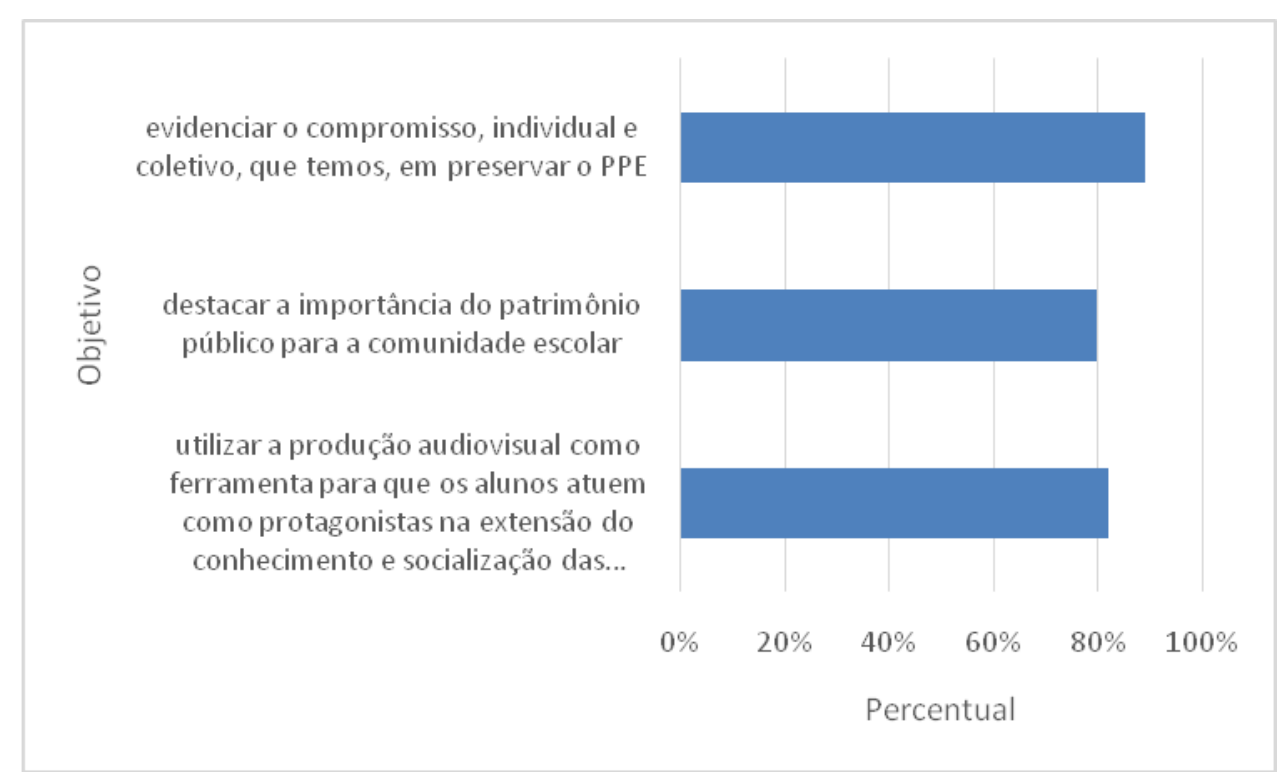

Fonte: Autores (2021).

Nesse sentido, a Atividade Extraclasse logrou êxito, no processo de conscientização e valorização do PPE, considerando como, positivo, o feedback dos alunos. Freire (1987, p.68) destaca que "ninguém educa ninguém, ninguém educa a si mesmo, os homens se educam entre si, mediatizados pelo mundo", nesse sentido, oportunizar o protagonismo do aluno nas questões administrativas, pedagógicas, sociais e culturais faz como ele se veja como parte integrante da instituição.

Verificamos se os participantes já se depararam com vestígios de depredação na escola. Conforme Gráfico 2, dos 86 respondentes, 26 declaram ter deparado com vestígios de depredação. 
Gráfico 2 - Você já se deparou com vestígios de depredação na escola.
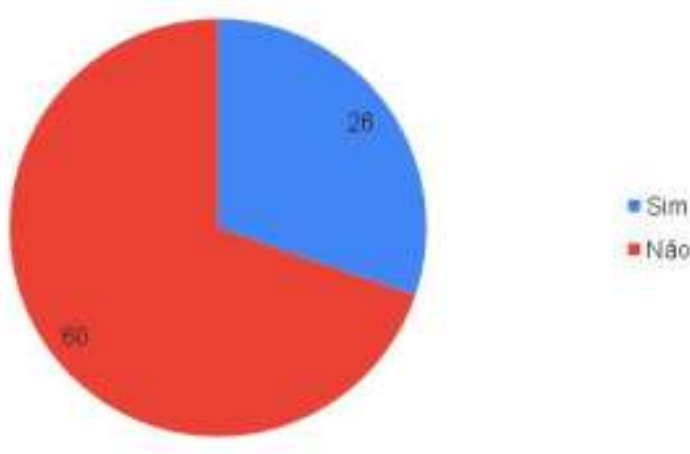

Fonte: Autores (2021).

Os participantes que confirmaram "já se depararam com vestígios de depredação na escola", relataram: qual(is) vestígio(s), como reagiram e o que sentiram. Constatamos que os banheiros, muros, carteiras, bancos e vidraças, são os mais depredados, com rabiscos, palavras de baixo calão, desenhos pornográficos, quebra de materiais, furtos e lixo. Quanto às reações foram de espanto, indignação, surpresa, decepção e impotência, como: "não poder fazer nada; não sabia o que falar; não conseguia pensar em nada para evitar". Os sentimentos relatados foram de mágoa, raiva, tristeza e sentir-se mal. Conforme Quadro 1.

Quadro 1 - Relatos de vestígios de depredação, reações e sentimentos.

\begin{tabular}{|c|c|c|}
\hline $\begin{array}{l}\text { Sim, os vestígios que eu vejo que } \\
\text { são mais comuns são banheiros } \\
\text { estragados propositalmente e } \\
\text { paredes e carteias sujas com } \\
\text { desenhos de cunho sexual. Minhas } \\
\text { reação foi de espanto, visto que } \\
\text { estamos em um ambiente escolar, e } \\
\text { deveria ser de senso comum } \\
\text { respeitar o ambiente que iremos } \\
\text { passar parte do nosso dia }\end{array}$ & $\begin{array}{l}\text { Sim, muitas vezes vi e presenciei } \\
\text { pessoas jogando lixo (papel, } \\
\text { chiclete, plástico...) no chão. Me } \\
\text { senti muito triste ao ver tal cena, } \\
\text { pois se trata de um espaço } \\
\text { compartilhado, tanto entre nós, } \\
\text { como também com os animais e } \\
\text { plantas ali pertencentes, se trata de } \\
\text { uma total falar de respeito com os } \\
\text { outros e o meio ambiente. }\end{array}$ & $\begin{array}{l}\text { Sim, já percebi o furto de um projetor de } \\
\text { parede uma vez (não presenciei, mas de um } \\
\text { dia para o outro o projetor havia } \\
\text { desaparecido e professores nós } \\
\text { comunicaram que foi um furto). Meu } \\
\text { sentimento foi de tristeza, pois alunos que } \\
\text { reclamam da falta de estrutura nas escolas } \\
\text { podem ser os mesmos que colaboram com a } \\
\text { depredação das mesmas. }\end{array}$ \\
\hline $\begin{array}{l}\text { Em minha antiga escola sim, como } \\
\text { as mesas rabiscadas com caneta ou } \\
\text { lápis. Sobre a minha reação, depois } \\
\text { que estava feito, eu não sabia oque } \\
\text { falar, sabia que não estava certo, } \\
\text { mas não conseguia pensar em nada } \\
\text { para evitar. }\end{array}$ & $\begin{array}{l}\text { Na IFTM não pois estamos em } \\
\text { ensino remoto, mas na minha escola } \\
\text { anterior já: nos banheiros os vasos e } \\
\text { torneiras alguns não funcionavam } \\
\text { pelo fato do mau uso, paredes } \\
\text { rabiscadas ,quebradas, mesas e } \\
\text { cadeiras quebradas, bancos no } \\
\text { refeitório estragados, etc. }\end{array}$ & $\begin{array}{l}\text { Quando tinham várias escritas nas paredes } \\
\text { da escola isso desrespeita muito mas sempre } \\
\text { nas férias eles pintavam as paredes, porém } \\
\text { na parte das mesas e cadeiras continuavam } \\
\text { escritas }\end{array}$ \\
\hline $\begin{array}{l}\text { Escrito de erox nos quiosques (não a } \\
\text { assinatura dos alunos, até pq acho } \\
\text { uma forma de lembrança, mas sim } \\
\text { de palavras feias), me senti muito } \\
\text { triste porque não tem necessidade. }\end{array}$ & $\begin{array}{l}\text { No IF não pois estou no } \\
\text { ensinamento remoto,mas na minha } \\
\text { na antiga escola já,como pessoas } \\
\text { chutando mesas e } \\
\text { cadeiras,rabiscando as } \\
\text { mesas,chutando as portas.. }\end{array}$ & $\begin{array}{l}\text { Sim. Me deparei com diversas situações em } \\
\text { outras escolas, como por exemplo, rabiscos, } \\
\text { quebra de materiais... Isso gera um } \\
\text { sentimento de decepção, pois algo que é } \\
\text { necessário ser preservado, é destruído }\end{array}$ \\
\hline $\begin{array}{l}\text { Sim, na verdade não os vestígios em } \\
\text { si. Mas minha escola antiga fez um } \\
\text { projeto bem interessante sobre } \\
\text { depressão e suas causas, e acredito } \\
\text { que ajudou muitas pessoas em meio } \\
\text { a está situação. }\end{array}$ & $\begin{array}{l}\text { Sim, muros quebrados e pichados na } \\
\text { minha antiga escola, e isso é muito } \\
\text { triste, pois querendo ou não é um } \\
\text { patrimônio de todos, que todos } \\
\text { devem cuidar. }\end{array}$ & $\begin{array}{l}\text { Sim, ja vi varios bancos quebrados na } \\
\text { escola. Minha reaçao foi neutra, mas é triste } \\
\text { por acabar com o local em que gostamos de } \\
\text { descansar. }\end{array}$ \\
\hline
\end{tabular}




\begin{tabular}{|l|l|l|}
\hline $\begin{array}{l}\text { Sim ,já ví pessoas destruírem } \\
\text { plantas, cartazes ,cadeiras } \\
\text {,etc....Minha reação foi chamar a } \\
\text { coordenação. Me senti triste e com } \\
\text { raiva }\end{array}$ & $\begin{array}{l}\text { Sim, como lixo no chão, bancos } \\
\text { quebrados, fico triste principalmente } \\
\text { no caso do lixo, é algo tão fácil e } \\
\text { simples jogar o lixo no lixo, e } \\
\text { mesmo assim as pessoas jogam no } \\
\text { chão ou na grama. }\end{array}$ & $\begin{array}{l}\text { Sim. Escritos nas mesas e cadeiras da escola } \\
\text { e nos banheiros, não fiquei surpresa pois } \\
\text { isso não é novidade em nenhum lugar, } \\
\text { indignação. }\end{array}$ \\
\hline $\begin{array}{l}\text { sim, nas minhas antigas escolas, } \\
\text { tinha as portas do banheiro tinha } \\
\text { muitas escrita, de canetas ou } \\
\text { corretivo }\end{array}$ & $\begin{array}{l}\text { Sim, como muros pichados, objetos } \\
\text { quebrados e outros. Meu sentimento } \\
\text { foi ficar chateada, pois é algo que } \\
\text { todos nós usamos e deveríamos } \\
\text { preservar. }\end{array}$ & $\begin{array}{l}\text { Sim. O estado das apostilas. Fiquei um } \\
\text { pouco surpresa porque alguns estavam } \\
\text { muito descuidados e isso é ruim para as } \\
\text { próximas pessoas que forem usar. }\end{array}$ \\
\hline $\begin{array}{l}\text { Sim, muitas vezes os alunos } \\
\text { quebram as mesas, rabiscam nelas, } \\
\text { sujam o banheiro etc }\end{array}$ & $\begin{array}{l}\text { sim, senti que aquele ali era meu } \\
\text { lugar e que realmente vai me ensinar } \\
\text { coisas pra levar para a vida }\end{array}$ & $\begin{array}{l}\text { Sim, ja ocorreram furtos. Me senti bem mal } \\
\text { pelo fato de não poder fazer nada a respeito. }\end{array}$ \\
\hline $\begin{array}{l}\text { Sim, muros pichados e carteiras } \\
\text { rabiscadas. Bom eu não fiz nada }\end{array}$ & $\begin{array}{l}\text { Sim, pichação de paredes, me senti } \\
\text { chateada com o descaso dos } \\
\text { estudantes }\end{array}$ & Sim, cacos de vidro, garrafas e lixo \\
\hline $\begin{array}{l}\text { Não visitei a IFTM ainda, por causa da pandemia, mas nas antigas escolas que eu frequentei sim. Pichação nos banheiros, } \\
\text { palavrões e desenhos poluídos. Normalmente vem dos alunos mesmo, que não respeitam a escola, nem as tias da limpezas, } \\
\text { que trabalham duro pra deixar a escola limpa e aconchegante para o estudo. Sempre que vejo elas trabalharem, ofereço } \\
\text { ajuda. Espero que um dia isso melhore }\end{array}$
\end{tabular}

Fonte: Autores (2021).

Com base nos relatos, os vestígios de depredação do PPE, é uma forma de agressão "indireta" à comunidade escolar. Proteger o patrimônio é proteger a si mesmo é garantir o seu bem-estar, conforme (Limberger, 1998, p. 83).

Desenvolver a capacidade de aprendizagem para formar atitudes e valores deve ser um trabalho coerente com as necessidades sociais, como a preservação do PPE, que serve especialmente à prestação de serviço público correspondente à um importante direito, que está diretamente ligado à melhoria da qualidade de vida das pessoas e de suas relações sociais.

Complementando o raciocínio anterior, verificamos, em uma escala de 1 (um) a 5 (cinco), qual o sentimento de pertencimento, do aluno, à escola. Temos no Gráfico 3 o predomínio em $51 \%$ de "muito" pertencimento e $27 \%$ de "Muitíssimo" pertencimento, ou seja, reafirma que os vestígios de depredação reverberam como um ataque às pessoas. A Usinagem FotoVídeo é a ferramenta que atende aos relatos anteriores, pois, é o ambiente, perfeito, para que o aluno possa fazer, saber o que falar, pensar e conseguir evitar.

Gráfico 3 - Em uma escala de 1 (um) a 5 (cinco), qual o seu sentimento de pertencimento à escola?

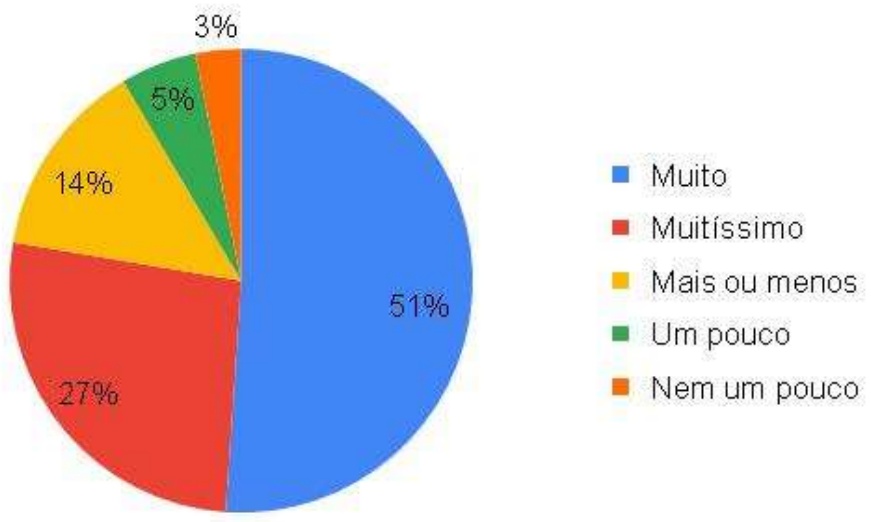

Fonte: Autores (2021). 
Analisamos a relação de pertencimento à escola e a questão do distanciamento do ambiente escolar, em decorrência da pandemia, visto que, em março de 2021 completou (01) um ano de ensino remoto. Questionamos os participantes se a questão da pandemia promoveu alguma reflexão sobre a importância do espaço escolar.

Gráfico 4 - Com os olhos voltados para a escola, nos responda: a questão da pandemia ajudou você a refletir sobre a importância do espaço escolar?

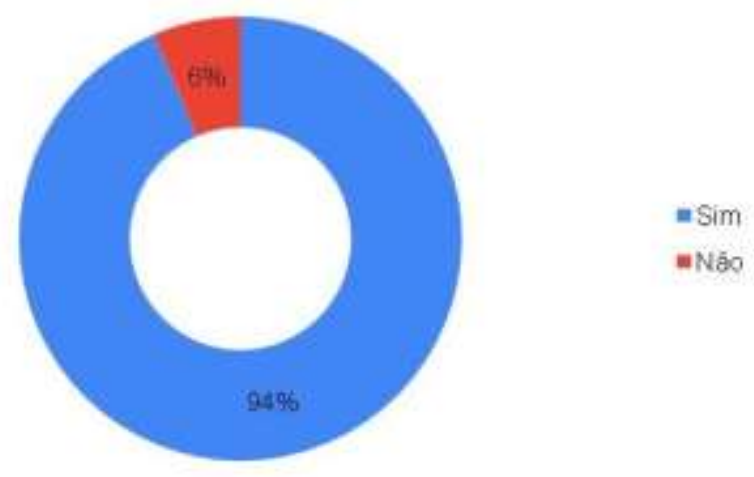

Fonte: Autores (2021).

Dos 94 respondentes, 88 disseram que sim e relataram as suas reflexões, conforme demonstrado no Gráfico 4. Selecionamos algumas a seguir:

- "O espaço escolar faz muita falta no meu cotidiano, sinto falta de estar no ambiente da escola e de todas as oportunidades que teríamos lá”.

- "A pandemia me ajudou a ver a falta que faz um espaço "próprio”, um local calmo, de certa forma, que nos auxilia na aprendizagem, sem falar na falta do contato com colegas e professores."

- “Como é bom ter aula prática, aula que você possa sentir e ver o que está sendo feito de bem perto."

- “As reflexões formam que a vida é muito curta para não darmos valor não só ao espaço estudantil, mas como em geral”.

A Usinagem FotoVídeo é uma Mídia Educativa formada pela produção individual dos alunos protagonista que trabalharam o tema PPE, que formularam a mensagem a ser transmitida, com base em registros fotográficos do IFTM-URA, cabendo aos pesquisadores unificar e editar os vídeos. Solicitamos a avaliação dos respondentes no que se refere à qualidade do conteúdo do vídeo. 
Gráfico 5 - Em uma escala de 1 (um) a 5 (cinco), quanto você avalia a qualidade do conteúdo do vídeo?

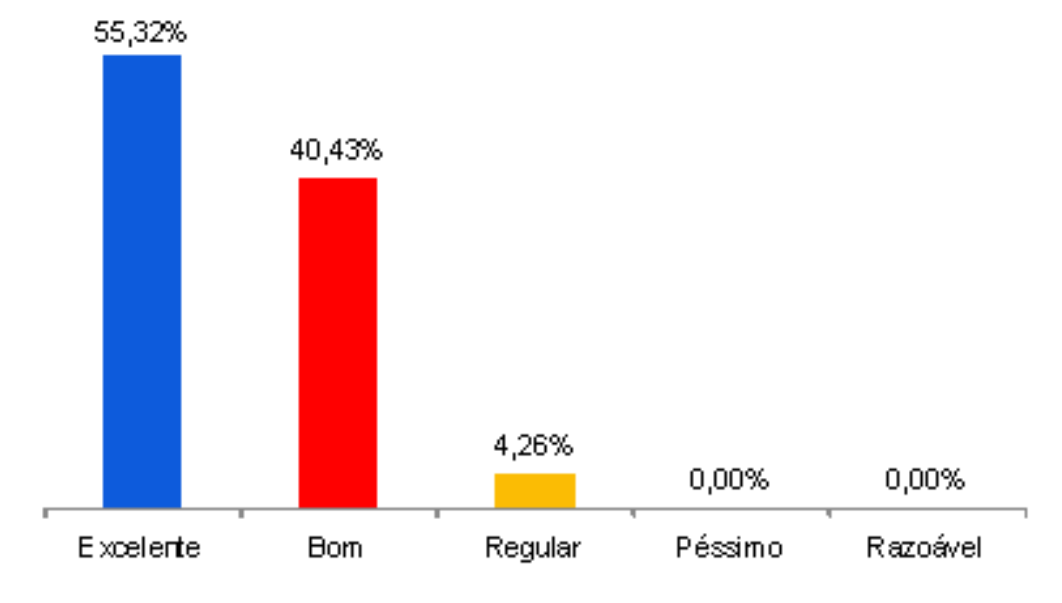

Fonte: Autores (2021).

Temos no Gráfico 5 que, somados, excelente e bom, a qualidade do conteúdo do vídeo atingiu 95,75\%, o que demonstra que a mensagem foi assimilada e aprovada pelos participantes/público alvo. Confirma-se, aqui, a valoração do aprendizado, do aluno para o aluno, por meio da produção audiovisual.

O Gráfico 6 avalia os níveis no processo de conscientização, que é o foco principal da atividade extraclasse.

Gráfico 6 - Em uma escala de 1 (um) a 5 (cinco), quanto você avalia o objetivo alcançado: "Conscientização da preservação do patrimônio público escolar"?

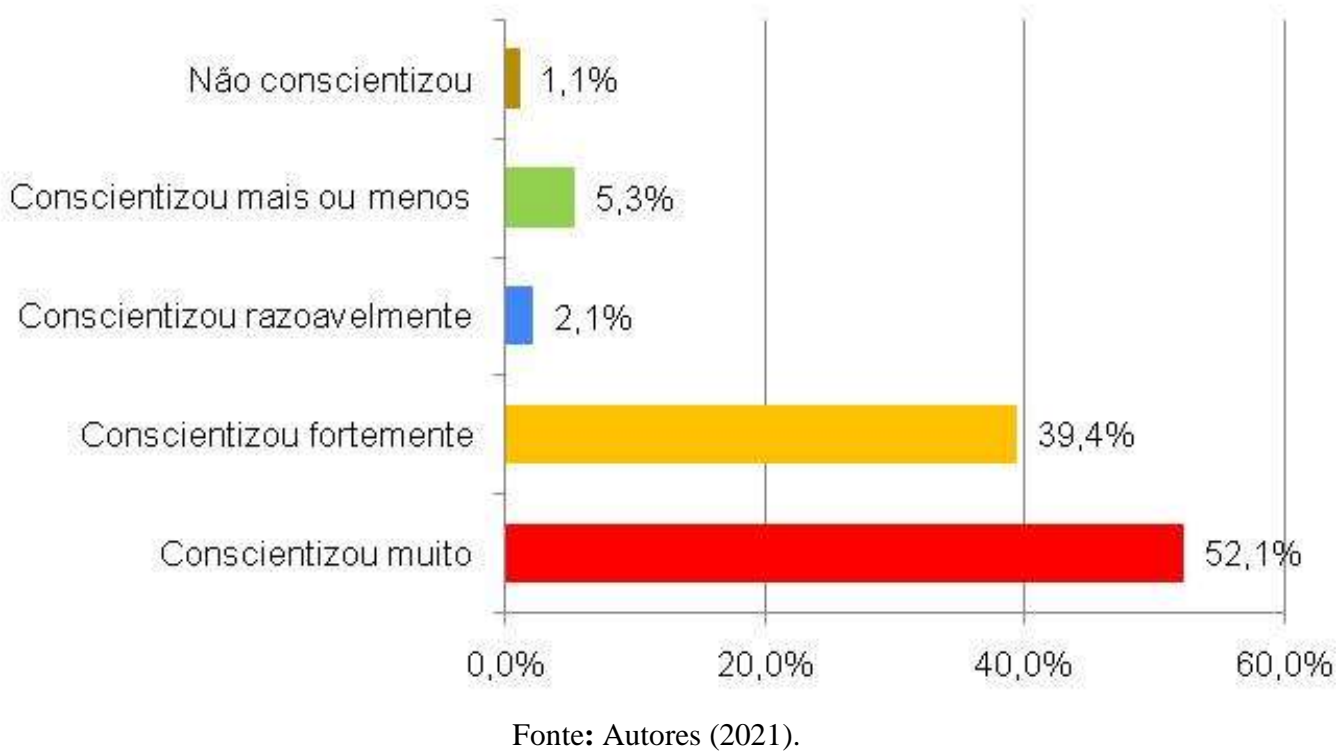

O Gráfico 6 revela que o objetivo de "conscientizar muito" alcançou 52,1\% dos alunos e "conscientizou fortemente" outros $39,4 \%$, totalizando $91,5 \%$ o que reafirmou o potencial formativo, linear, entre alunos, no propósito de conscientizar sobre importância do PPE.

O IFTM, no que se refere ao EMI, recebe novos alunos, anualmente. Da mesma forma o processo de conscientização para a preservação do PPE deve ter novas edições e os participantes desta atividade são os protagonistas mais indicados para este trabalho, para tanto, perguntamos como eles avaliam o grau de importância de ações voltadas para a preservação do PPE. 
Gráfico 7 - Como você avalia o grau de importância de ações voltadas para a preservação do patrimônio público escolar?

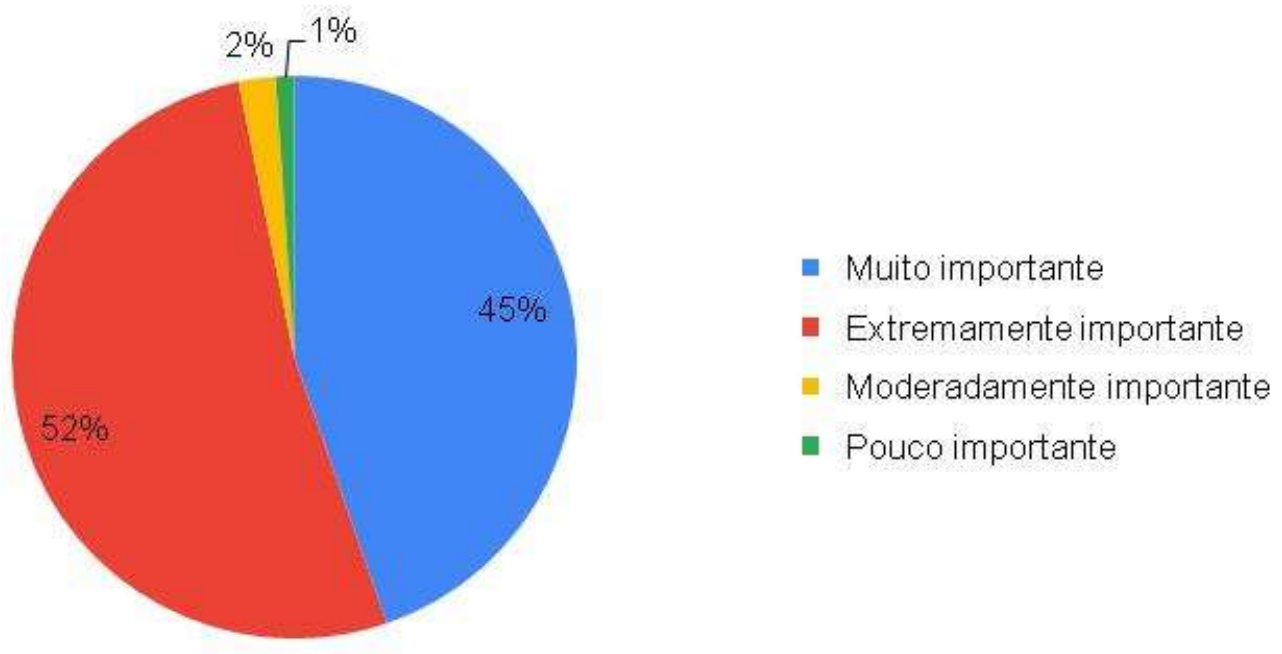

Fonte: Autores (2021).

Os resultados apontam que, $72 \%$ dos entrevistados declaram que tais ações são "Extremamente importantes" e mais 24\% declaram que é "Muito Importante", conforme Gráfico 7, validando a realização de outras ações voltadas para a conscientização da preservação do PPE.

No seguimento à consultas buscamos as considerações dos respondedores quanto ao protagonismo dos alunos e o grau de importância da participação deles nas ações do IFTM. Como resultado, no Gráfico 8, revelaram que 52\% dos partícipes consideram "extremamente importantes" o protagonismo dos alunos na ações do IFTM, seguido de 45\% que consideram "muito importante" e, somados, "moderadamente e ligeiramente importante", $3 \%$.

Gráfico 8 - Como você avalia o grau de importância do protagonismo dos alunos nas ações do IFTM (ou seja, os alunos participarem da elaboração, execução e reflexão de algumas ações no IFTM)?

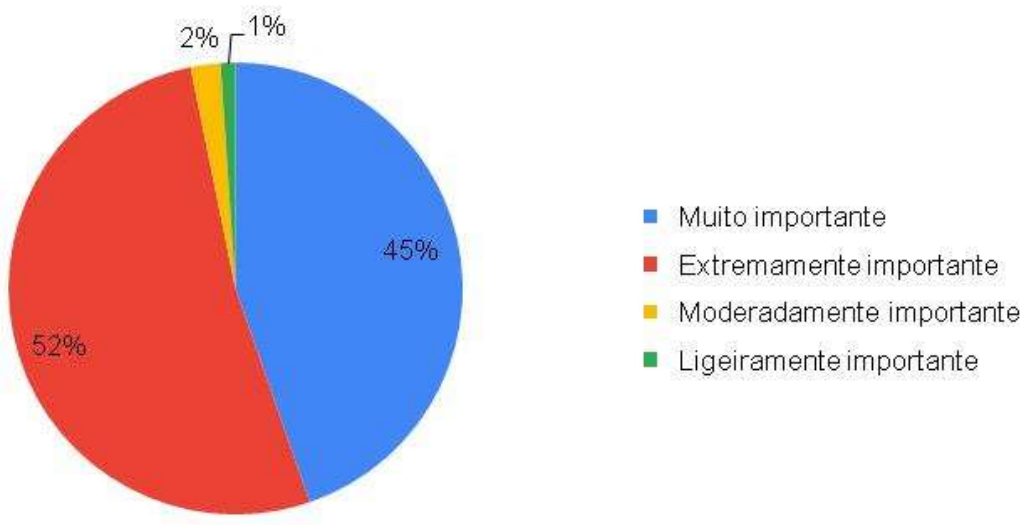

Fonte: Autores (2021).

O desempenho dos protagonistas foi além do trabalho artístico, eles atuaram nos processos de elaboração, execução e reflexão em uma atividade na escola, aumentando o grau de pertencimento à escola (Silva, 2018).

Os sentimentos de pertencimento e identidade no ambiente escolar possuem significados, sentidos e valores que são lapidados a cada momento. Haja vista que o contexto escolar oferece inúmeras possibilidades enriquecedoras capazes 
de desenvolver habilidades de ação e reflexão do aluno em relação as suas condutas e valores sociais, vemos de suma importância explorar a questão ambiental para o desenvolvimento de sentimentos de pertencimento e identidade.

Finalizamos a Atividade Extraclasse colhendo os comentários e sugestões sobre o projeto Usinagem FotoVídeo, conforme Quadro 2.

Quadro 2 - Comentários e sugestões.

\begin{tabular}{|c|c|c|}
\hline $\begin{array}{l}\text { Um bom projeto de } \\
\text { conscientização para alunos e } \\
\text { super importante para a } \\
\text { preservação do patrimônio. }\end{array}$ & $\begin{array}{l}\text { Achei tudo muito lindo,bem } \\
\text { organizado e espero brevemente } \\
\text { conhecer esse lugar incrível }\end{array}$ & $\begin{array}{l}\text { Devia aparecer todos os alunos e } \\
\text { professores no vídeo. }\end{array}$ \\
\hline $\begin{array}{l}\text { O vídeo foi super informativo } \\
\text { trouxe mais ainda a consciência de } \\
\text { cuidar e agradecer do que é nosso, } \\
\text { e uma maior vontade de conhecer o } \\
\text { campus (Ps: Sou do } 1^{\circ} \text { ano) }\end{array}$ & $\begin{array}{l}\text { Eu super apoio do projeto } \\
\text { Usinagem FotoVideo, acho que é } \\
\text { de extrema importância os alunos } \\
\text { participarem e preservarem o } \\
\text { patrimônio público escolar. }\end{array}$ & $\begin{array}{l}\text { Continuem fazendo esse belo } \\
\text { trabalho,infelizmente não tive a } \\
\text { oportunidade de ir ao IF mas tenho } \\
\text { grandes expectativas,espero que } \\
\text { esteja muito bem preservado.Estou } \\
\text { ansiosa pra visitar esse lugar. }\end{array}$ \\
\hline $\begin{array}{l}\text { Um vídeo super instrutivo, e que } \\
\text { realmente tem o objetivo de } \\
\text { mostrar a importância da } \\
\text { preservação dos patrimônios } \\
\text { escolares!!! }\end{array}$ & $\begin{array}{l}\text { Gostei muito do vídeo, e de } \\
\text { conhecer um pouquinho dos } \\
\text { espaços dentro do if, ele } \\
\text { conscientiza bastante a importância } \\
\text { da preservação do patrimônio } \\
\text { público da escola }\end{array}$ & $\begin{array}{l}\text { Melhor áudio, e mais participantes } \\
\text { para destacar com maior } \\
\text { efetividade o objetivo do vídeo. }\end{array}$ \\
\hline Estão de parabéns & Muito bom adoreii & Muito bom para alguns alunos. \\
\hline $\begin{array}{l}\text { ficou muito bom! parabéns pelo } \\
\text { projeto }\end{array}$ & $\begin{array}{l}\text { Muito necessário a escola é } \\
\text { importante para todos. }\end{array}$ & $\begin{array}{l}\text { Queria apenas comentar que achei } \\
\text { um vídeo muito bom e importante, } \\
\text { parabéns }\end{array}$ \\
\hline $\begin{array}{l}\text { Apenas quero parabenizar pela } \\
\text { excelente abordagem desse tema } \\
\text { tão importante. }\end{array}$ & $\begin{array}{l}\text { Parabéns pelo projeto,é muito } \\
\text { importante. }\end{array}$ & $\begin{array}{l}\text { Fazer um tour por todo if, se quiser } \\
\text { me chama que eu faço kkkk }\end{array}$ \\
\hline $\begin{array}{l}\text { Eu amei o vídeo, e achei super } \\
\text { explicativo. ;) }\end{array}$ & $\begin{array}{l}\text { acho que não tem nada a } \\
\text { acrescentar, o vídeo ficou muito } \\
\text { bom! }\end{array}$ & $\begin{array}{l}\text { Ficou ótimo! parabéns aos } \\
\text { envolvidos }\end{array}$ \\
\hline Gostei muito! & Amei o vídeo. & Excelente iniciativa \\
\hline $\begin{array}{l}\text { Mostrarem mais os trabalhos de } \\
\text { aula prática }\end{array}$ & $\begin{array}{l}\text { É um projeto muito lindo e bem } \\
\text { desenvolvido. }\end{array}$ & $\begin{array}{l}\text { Eu amei o vídeo, me fez refletir } \\
\text { muito! }\end{array}$ \\
\hline
\end{tabular}

Fonte: Autores (2021).

\section{Avaliação da Usinagem FotoVídeo}

A proposta de uma intervenção pedagógica, voltada para os alunos do EMI do IFTM-URA, com vistas à promoção da conscientização da preservação do PPE durante a pandemia da Covid-19, partiu da inquietação, pré-pandemia, dos pesquisadores diante os atos de depredação do PPE no IFTM-URA, comumente praticados pelos próprios usuários, mais especificamente pelo alunado. Pensando na possibilidade do retorno às aulas presenciais, mesmo que híbridas, e nos potenciais autores das depredações, o presente estudo objetivou desenvolver uma atividade extraclasse e promover a conscientização da preservação do PPE, protagonizada pelos alunos do EMI, por meio da produção audiovisual, denominada Usinagem FotoVídeo, desenvolvida na modalidade virtual, respeitando as medidas de distanciamento social. Cordeiro (2020, p. 4) diz a crise oportunizou novos aprendizados e espera que a educação volte mais fortalecida.

É importante colocar que o ensino nunca mais voltará a ser o que era antes. Abre precedentes para novas formas de aprender e reaprender, nos libertamos das paredes da sala de aula e descobrimos um mundo de oportunidades nas mãos de crianças, jovens e adultos. Os professores vivenciaram novas formas de ensinar, novas ferramentas de 
avaliação e os estudantes entenderam que precisam de organização, dedicação e planejamento para aprender no mundo digital.

O audiovisual "Usinagem FotoVídeo" ascendeu os holofotes sobre o protagonismo estudantil e socializou a importância do PPE e o compromisso, de todos, em preservá-lo, visto que, as declarações dos alunos que disseram já terem se deparado com vestígios de depredação, evidenciam os dissabores causado por "atores anônimos". Isso se justifica porque, com maior ou menor intensidade, esse grupo de participantes se vê pertencente à escola e, devido à suspensão das aulas presenciais para contensão da pandemia, eles sentem muita falta da conexão aluno/escola. Fernandes (2012) apud Willms (2003) fala de envolvimento e pertencimento à escola:

[...] ao mencionar que o envolvimento escolar é visto como uma disposição do aluno para aprender a trabalhar com os outros e a envolver-se na instituição escolar, o que se expressa nos sentimentos de pertença do aluno e na sua participação, quer em atividades escolares, quer em extracurriculares.

Dentre outras avaliações, os participantes elogiaram a qualidade do vídeo, o propósito de conscientização da preservação do PPE foi alcançado e foram classificados como, "extremamente e muito importante", respectivamente, o grau de importância da ação voltada para tema PPE e o grau de importância do protagonismo dos alunos em algumas ações do IFTM. Quanto aos comentários e sugestão sobre o projeto Usinagem FotoVídeo, muitos elogios e agradecimentos.

\section{Considerações Finais}

A produção audiovisual como ferramenta para aprendizagem pode ser utilizada pelos educadores, independente da sua área de atuação. O processo exige poucos recursos como celular, máquina fotográfica e computador. Na internet existem softwares gratuitos para edição, contudo, é imprescindível que os alunos estejam motivados para que esse modal esteja mais próximo do entretenimento, do lazer e que a aprendizagem seja uma consequência.

Recomendamos traçar modalidades de ação, sempre com suporte pedagógico, que estabeleçam relações diretas com disciplinas por meio da arte, ou seja, de forma lúdica, um ator aprendendo, bem como, temas que não constam no currículo escolar, assuntos que atendam às necessidades da comunidade dentro e fora da escolar.

Para trabalho futuros sugerimos a oferta de oficinas, periódicas, com temáticas voltadas para a PPE, vez que, trata-se de um "processo de conscientização", o que requer um exercício continuo. Nas referidas oficinas o trabalho de iniciação à produção audiovisual tenham como foco o protagonismo dos estudantes, o registro do trabalho executado por eles (sempre com um suporte pedagógico), visando o compartilhamento e a propagação desta formação cidadã.

\section{Referências}

Almeida, T. J. B. (2018). Educação ambiental e valorização da ética para o cuidado do ambiente escolar. Dissertação de mestrado, Universidade Católica, Salvador, BA, Brasil. http://ri.ucsal.br:8080/jspui/handle/prefix/429.

Boarini, M. L. (2013). Indisciplina escolar: uma construção coletiva. Psicologia Escolar e Educacional, 17(1), 123-131. https://doi.org/10.1590/S141385572013000100013.

Brasil (1990). Lei $n^{\circ} 8069$, de 13 de julho de 1990. Dispõe sobre o Estatuto da Criança e do Adolescente e dá outras providências.

Diário Oficial da União, Brasília, DF, jul. 1990. http://www.planalto.gov.br

Castaman, A.S., \& Rodrigues, R. A. (2020). Educação a distância na crise Covid-19: um relato de experiência. Research, Society and Development. 9(6), 1-26. http://dx.doi.org/10.33448/rsd-v9i6.3699.

Cipolla, L. E. (2016). Resenha: Aprendizagem Baseada em Projetos: A Educação Diferenciada para o Século XXI. (William N. Bender 2015). Administração: Ensino e Pesquisa. 17(3), 567-585. https://doi.org/10.13058/raep.2016.v17n3.440.

Cordeiro, K. M. A. (2020). O impacto da pandemia na educação: a utilização da tecnologia como ferramenta de ensino, IDAAM, Manaus, AM, Brasil. http://repositorio.idaam.edu.br/jspui/handle/prefix/1157. 
Domingues, G. C. M. C., \& Silva, B. E. (2017). Depredação do patrimônio público escolar: intervenção pedagógica na escola estadual Dr. Geraldo Parreiras de João Molevade. Revista Doctum. 1(2), 1-17. http://revista.doctum.edu.br/index.php/EDU/article/view/161.

Felippe, M. L., Raymundo, L. S., \& Kuhnen, A. (2012). Frequência autoreportada de vandalismo na escola: questões de gênero, idade e escolaridade. PSICO. 43(2), 243-250. https://revistaseletronicas.pucrs.br/ojs/index.php/revistapsico/article/view/11702.

Fernando, H. M. R. (2012). Envolvimento do aluno na escola um estudo em escolas de são Miguel. Dissertação de mestrado, Universidade dos Açores, Ponta Delgada, Portugal. https://repositorio.uac.pt/bitstream/10400.3/2047/1/DissertMestradoHelderManuelRegoFernandes2013.pdf.

Freire, P. (1987). Pedagogia do Oprimido. Paz e Terra.

Gomes, A. H. (2011). "Olhos vendados”: a experiência criadora na produção de um curta-metragem. Dissertação de mestrado, Universidade Federal de Santa Catarina, Florianópolis, SC, Brasil. https://repositorio.ufsc.br/xmlui/handle/123456789/95871.

Limberger, T. (1998). Atos Lesivos ao Patrimônio Público: os princípios constitucionais.

Lindenmeyer, S., Schmidt, M., Matias F., \& Bez, M. R. (2016). «-Eu que fiz! » a produção de curtas-metragens como estratégia tecnológica de autoria, aprendizagem e inclusão (maio 2016). Teknos. 16(2), 47-58. https://doi.org/10.25044/25392190.821.

Moura, M. R. L. (2010). O grêmio estudantil na gestão da escola democrática: protagonismo e resiliência ou despolitização das práticas formativas? Revista de Ciências da Educação. 23, 273-292. https://doi.org/10.19091/reced.v0i23.70.

Pires, E. G. (2010). A experiência audiovisual nos espaços educativos: possíveis interseções entre educação e comunicação. Educ. Pesquisa. 36(1), 281-295. https://doi.org/10.1590/S1517-97022010000100006.

Rosa, M. J. A. (2010). Violência no ambiente escolar: refletindo sobre as consequências para o processo ensino aprendizagem. Gepiadde. 8, 143-158. https://seer.ufs.br/index.php/forumidentidades/article/view/1785.

Santagueda, V. M. P., Cantalice, A. S., Silva, A. B., \& Mafort, M. E. (2019). Comportamento sustentável: promoção da consciência ambiental por meio de gincana. Research, Society and Development. 9(2), 1-16. http://dx.doi.org/10.33448/rsd-v9i2.1976.

Silva, A. S. (2018). Sentimentos de pertencimento e identidade no ambiente escolar. Revista Brasileira de Educação em Geografia. 8(16), https://www.revistaedugeo.com.br/ojs/index.php/revistaedugeo/article/view/535

$130-141$.

Thiollent, M. (2011). Metodologia da Pesquisa-ação. Cortez.

Vieira, R. M., Morais, L. S., Barbosa, J. A. S., Maia, C. L. S., \& Alves, A. F. (2012). Avaliação dos atos de depredação e suas motivações no IFPB Campus João Pessoa. Muito além de uma questão educacional. Principia. 21, 11-20. https://periodicos.ifpb.edu.br/index.php/principia/article/viewFile/132/107

Zanini, R., \& Berndard, G. (2013). O cinema na escola: possibilidades múltiplas. Monografia de especialização, Universidade Federal de Santa Maria, Santa Maria, RS, Brasil. https://repositorio.ufsm.br/bitstream/handle/1/607/Zanini_Rejane.pdf?sequence=1\&isAllowed=y. 